\title{
Financial Attributes and Investor Risk Tolerance at the Nairobi Securities Exchange - A Kenyan Perspective
}

\author{
T. Olweny ${ }^{1}$, G. S. Namusonge ${ }^{2} \&$ S. Onyango ${ }^{3}$ \\ ${ }^{1}$ JKUAT, Kenya \\ ${ }^{2}$ EPD JKUAT, Kenya \\ ${ }^{3}$ School of Business, KCA University, Kenya \\ Correspondence: T. Olweny, JKUAT, Kenya. E-mail: toolweny@yahoo.com
}

Received: September 13, 2012 Accepted: January 8, 2013 Online Published: February 28, 2013

doi:10.5539/ass.v9n3p138

URL: http://dx.doi.org/10.5539/ass.v9n3p138

\begin{abstract}
The inclination for optimizing returns by taking maximum risk has implications for both individual investors, as well as fund managers. For the former, risk tolerance will determine the appropriate composition of assets in a portfolio, which is optimal in terms of risk and returns relative to the needs of the individual. For fund managers, the inability to effectively determine investor risk tolerance may lead to homogeneity among investment funds. This paper investigates the extent to which financial attributes affect individual investor risk tolerance at the Nairobi Securities Exchange (NSE), Kenya. Financial attributes in this study were measured in two main aspects: individual monthly earnings income and home ownership. A sample of 500 Central Depository System (CDS) account holders was selected from a population of 932,510 investors at the NSE. Single independent variable cross tabulation on risk tolerance as well as paired cross tabulation on the dependent variable was performed. Analysis of variance was also used to determine how each group of the independent variable affects the dependent variable. Ordinal logistic regression model (OLRM) was employed to establish the contribution of financial attributes on risk tolerance. Single independent variable cross tabulation revealed that home owners were more risk tolerant than non owners. However, one way Analysis of Variance revealed that the variable had a $\mathrm{P}$ value of 0.710 , hence not significantly affecting risk tolerance. The result of ANOVA on income was significant at a $\mathrm{P}$ value of 0.014 individual earnings, hence influences risk tolerance. Risk tolerance increased with earnings up to very high, except for those who earned more than 120,000 per month. OLMR fitted well with a significance level of 0.027 less than $\alpha=5 \%$, although it showed that home ownership is not a significant determinant at a $\mathrm{P}$ value of 0.761 . For every single unit of home ownership for those with homes to those without, the expected log of odds increased by 0.060 as the threshold of risk tolerance increased, holding other factors constant. Income levels for those earning 90,000-120,000 per month showed a P value of 0.006 , hence income was a major determinant of risk tolerance. For every single unit increase of investors earning 90,000-120,000, the expected ordered log of odds of risk tolerance reduced by 1.077 as the threshold of risk tolerance increased, holding other factors constant. Therefore fund managers, investment advisors and individual investors should consider the contribution of financial attributes in financial decision making.
\end{abstract}

Keywords: risk tolerance, investment, financial attributes

\section{Introduction}

Risk tolerance levels of present and potential investors are rarely accorded sufficient attention in the investment decision making process. Apparently, Kenyan fund managers and investment advisors may not be adequately assessing and taking into account the factors that influence the degree of willingness of an individual to accept risk, when constructing their investment portfolios, (NSE, 2008). Besides, they rarely consider the variables that inform the degree to which an investor is willing and able to accept the possibility of uncertain outcomes to an economic decision. Individual investors equally seldom evaluate their risk aversion, when making investment choices. Their willingness to take risks may be informed by psychological variables such as education level, financial literacy, home ownership, marital status and income among others. Studies from the developed world such as Davey (2002), indicate that investment advisors have specific tools for evaluating ones' risk tolerance on the onset of investment advice; their tool incorporates some aspects of the variables above. Such tools promote efficiency in the financial market as envisaged in Kenya vision 2030 under the economic pillar of financial 
services.

Many Kenyans rarely consult investment advisors licensed by the Capital Markets Authority (CMA), whenever they intend to invest in the stock market. These advisors also tend to avoid provision of services to individual investors because of their low income level instead, they prefer dealing with institutional investors who have regular income to pay advisory charges. Brokerage firms and investment banks have played advisory roles to investors in Kenya since independence, (CMA, 2010). This advice however, is rarely objective because their principle aim is to convince the investors to open an account for their custody and earn commissions or brokerage fees. They seldom evaluate a person's investment policy for relevant decision making. In addressing the problem above, the following question need to be answered: What are the implications of financial attributes on risk tolerance and portfolio selection? The study therefore classified financial attributes into two main areas: home ownership and income level of investors.

Specific objectives are:

1) To determine the relationship between home ownership in developing countries and investor risk tolerance.

2) To evaluate the effect of income level on risk tolerance in a developing nation such as Kenya.

\section{Literature}

Arrow and Pratt (1965), conducted a ground breaking research on the above factors in the United States using an experimental design. They observed that investors with high risk aversion were less willing to take risk, since the price of bearing it- risk premium is much larger. In their approach, the main factor of risk aversion was wealth of the investors. They established that risk aversion is an inverse of risk tolerance as confirmed by the various researches cited in the literature review. Their method of risk aversion measurement was based on optimal portfolio. In Sweden, Palsson (1996), looked at the effect of investor's wealth on risk tolerance using a sample of 600 respondents. He used a cross sectional data in an attempt to establish whether the degree of risk aversion varies with household characteristics. After regression analysis, Palsson determined that wealthier households were more likely to engage in risky assets than less wealthy ones.

Sung and Hanna (1996), also studied a sample of 2659 respondents aged 16-70 in the United States, with their main independent variable being non investment income. They established that non investment income had a positive effect on risk tolerance. In the sample, they found out that $60 \%$ of households were risk tolerant and $40 \%$ were not. Testing on subjective and objective risk tolerance in U.S.A, Hanna and Chen (1997), used investment horizon as the main dependent factor. The effect of subjective risk tolerance was investigated based on investments relative risk aversion. Low subjective tolerance was equivalent to relative risk aversion of 10 or more, moderate between 3 and 9 and high aversion under 3. From their sample, they found that for many households, financial assets increase as human wealth decreases, while financial assets to wealth ration increased with an individual's age. Barsky et al (1997), focused on the impact of wealth on risk tolerance in the United States using hypothetical income gamble questions that were part of the 1992 health and retirement study. The Health and retirement study began in 1992 as a large biennial panel survey of Americans over the age of 50 and their spouses' ( further information on the survey and details available at http.hrsonline.isr.umich.edu.)

They constructed measures using Arrow and Pratt utility concept of risk aversion and established that households differed markedly in their willingness to bear risk. Moreover, risk aversion had considerable productive power on risky choices households actually made. A study based on gamble questions was further conducted by Donkers et al (1999); applying subjective measures of risk tolerance in the Netherlands, and asking gamble questions to respondents. They note that due to possible uncertain property prices and maintenance costs, home owners could view their houses as being risky investments, and would thus not be willing to take any additional risks such as investments in stock. They determined a positive correlation between actual property values and risk tolerance attitudes.

The effect of household's income and properties have been examined by Haynes et al (2001), who applied survey consumer finances data in the United States of America. They conducted personal interviews with a large number of randomly selected households, with a population of 2780 families sampled by multistage. They report that risk tolerance is consistent with attitude and behavior of business owners. The share of risky assets held by family business owners increased as the level of risk tolerance increased. $36 \%$ of business owners willing to take substantial risks had most risky asset portfolio, 76-100\% were in risky assets as compared to only $16-24 \%$ of owners, who were willing to take lower level of risks and had the same highest risky portfolio.

Angelika et al (2007), in Netherlands employed a German survey and vitality education (SAVE) study. SAVE study is household panel that is designed to gain a broad understanding of savings and investment behavior of 
households or a Markov chain Monte Carlo algorithm for multiple imputations in large surveys. With a total population of 2305 households to study risk attitude and asset choice, they applied Matrix analysis and concluded, that higher levels of risk aversion were associated with lower holdings of stocks and retirement insurance contracts. They also considered asset holding percentage with respect to increases in wealth, risk tolerance and impatience of investors. They report that marginal effects for wealth are largest for savings account, while a smaller proportion of bondholders $(8 \%)$ were rich, risk tolerant and impatient.

Concerning the influence of business ownership on risk tolerance, Wang and Hanna (2007), used revised Survey Consumer Finances (SCF) data from 1992-2004 in America and classified stock ownership into three types of households: those who do not own business, those that own and manage a business, and those that do not manage a business. They then investigated risk tolerance differences among the three types of households. In addition, they sought to determine the differences in stock ownership among these households using stock ownership as an indicator of household risk taking behavior. Ownership of a business was measured using a survey question.

The SCF also classified privately owned businesses into those which the family had an active management role and those which they did not. Of the 21471 households interviewed in the survey, 13.3\%owned businesses, $91.9 \%$ were manager owners and $18.8 \%$ were non manager owners. They analyzed data by logit and established that non manager business owners were most likely to be willing to take risks than manager owners. Manager business owners were more willing to take risk than non owners, but were less likely to own stocks than other similar non owner households. They also found that households with a child are less willing to take some risk than those without, while non coupled households were more likely to take substantial and high risk than coupled households. They concluded that socio-cultural backgrounds have a bearing in risk taking.

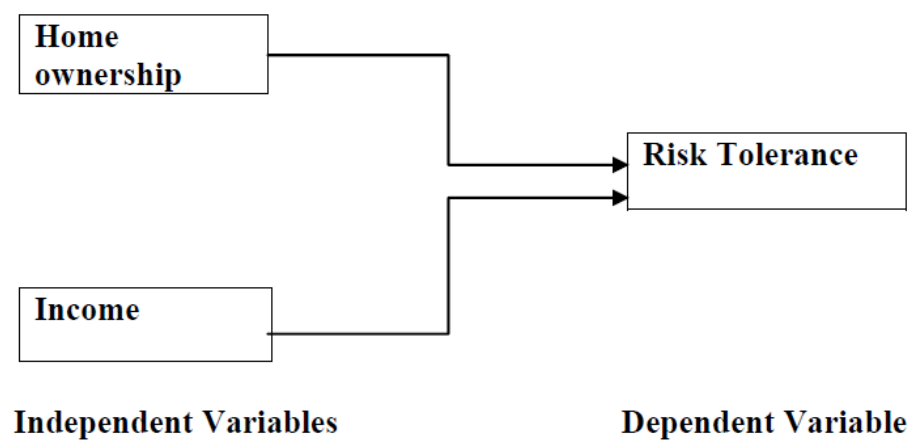

Figure 1. Conceptual model

\section{Methodology}

\subsection{Research Design}

Kelinger (2004), defines research design as the plan, structure and strategy of investigation conceived so as to obtain answers to research questions. It includes the overall scheme, an outline for each hypothesis and their operational implications as well as the methods used to gather and analyze data. Cooper and Schindler (2008), classifies business research designs using descriptors such as the purpose of study, method of data collection, power of the researcher to produce effects in the variables under study, time dimension, scope of the study, research environment and the perception of the participants of the research activity. Depending on the descriptors, an appropriate option of research design is selected ranging from exploratory studies, descriptive studies or causal studies. A descriptive research study may be simple or complex and may be done in many settings. Simple descriptive studies concerns a univariate hypothesis or questions about, or state something about size, form, distribution or existence of a variable. A complex descriptive study on the other hand, involves collecting evidence leading to causal questions, correlation between independent variables and probabilities of interrelationship among the variables in a research. This study adopted a complex descriptive approach to evaluate the determinants of an individual investor's risk tolerance. Investor attributes such as biopsychological, financial and sociocultural were hypothesized to influence an individual's inclination towards risk. Data on the said attributes which include investor's age, financial literacy, income, household status, home ownership as well as racial/ethnic orientation were obtained through a questionnaire. 


\subsection{Target Population}

The population of investors from whom a sample for assessing individual risk tolerance in Kenya, comprised of all investors holding accounts with the Central Depository Systems Corporation (CDSC), was drawn. The total number of investors was 932,510 as at $30^{\text {th }}$ September 2010 (CMA, 2010). The CDSC was created by the Central Depository Act 2000 to establish and operate a system for a central handling of securities in Kenya, provide immobilization and eventual dematerialization of, and dealings in securities deposited there with in the country and for connected purposes; such securities are immobilized or dematerialized and dealings in respect of those securities are affected by means of entries in securities accounts without physical necessity of certificates. The CDSC provides a reliable source of demand for investments in the Kenyan capital market. The system has created a databank which is ideal for a framework for establishing whether investment managers, advisors and individuals assess their risk tolerance levels before selecting an investment portfolio given limited resources.

\subsection{Sampling Frame and Technique}

Since the population variance with respect to the dependent variable is unknown and also because a large portion of the predictor and criterion variables are measured as categorical and not continuous variables, the sample size estimate follows the recommendations by Bartlett et al. (2001) and Sekaran (2003), in the form shown below:

$$
\begin{gathered}
\mathrm{n}_{0}=\frac{(\mathrm{t})^{2} *(\mathrm{p})(\mathrm{q})}{(\mathrm{d})^{2}} \\
\mathrm{n}_{0}=\frac{(2.58)^{2} *(0.75)(0.25)}{(0.05)^{2}}=499.23
\end{gathered}
$$

Same as 500 people

Where $n_{o}$ is the sample size, " $t$ " = the value for the selected alpha level of $1 \%$ in each tail to increase precision, hence 2.58; (p) (q) =estimates of variance; where "d" is the acceptable margin of error for the proportion being estimated, that is error researcher is willing to accept $=5 \%$. The selected sample size, of 500 , is further informed by three factors: the desire to reduce the sampling error, many respondents may not fill all the details and lowering the number of valid responses, and the fact that the target population is expected to be highly heterogeneous with respect to a number of the internal variables under study.

A random sample of 500 individual investors was selected from 22 investment banks and 3 stock brokers which represent the entire licensed brokerage firms by the CMA as at 31 December 2010. A simple random sample was drawn from all the account holders in each investment bank and stock broker, which is considered manageable in terms of costs and representative of all custodians in contact with individual investors.

\subsection{Data Analysis}

Descriptive statistics cross tabulation; ordinal logistic regression and correlation analysis was employed to analyze the data. Histogram of risk tolerance and mean, median score and standard deviations forms descriptive statistics, which were further analyzed through statistical package for social sciences (SPSS 17) to determine various coefficients, standard error, regression equations tests, Wolfowitz Wald test, one way as well as paired Analyses of variance (ANOVA) was performed on the data. Ordinal logistic regression was applied to test the implication of individual variable in the determination of an individual's risk tolerance in relation to other variables that have specific ordered characteristics. The log of odds for increase or decrease was obtained for each coefficient of the variables holding others variables constant as explained in section 4 below. Each value of the independent components was obtained in the questionnaire and a score ranging to a scale of 47 using a 13-item risk tolerance measurement questionnaire (Grable \& Lyton, 1999).

An ordinal logistic regression analysis was preferred, since risk tolerance is deemed to be a function of these selected variables of financial attributes of an individual; home ownership and income (earning level) as variables have been categorized into ordered responses. For home ownership investors were classified into two: those who had homes and those without homes. Income levels were categorized into five groups those who earn under Ksh 30000 per month, between 30000-60000,60000-90000,90000-120000 and over 120000.The dependent variable was converted in to an ordinal scale with five categories of scores. The maximum possible score was 47. A score of 33 and above categorized as very high risk tolerances, 29-32; Above average risk tolerance, 23-28 average risk tolerance ; 19-22 below average while 0-18 low risk tolerance. The equations for this model are as follows:

$$
\operatorname{logit}(p)=\log [p /(1-p)]=\ln [p /(1-p)]
$$




$$
\operatorname{logit} \mathrm{p}=\frac{\mathrm{p}}{1-\mathrm{p}}=\beta_{0}+\beta_{\mathrm{h}} \mathrm{H}+\beta_{\mathrm{i}} \mathrm{I}+\varepsilon_{\mathrm{i}}
$$

Where $p$ is the probability of risk tolerance of an investor

$$
p=\frac{e^{\beta_{0}+\beta_{h} \mathrm{H}+\beta_{\mathrm{i}} \mathrm{I}}}{1+\mathrm{e}^{\beta_{0}+\beta_{\mathrm{h}} \mathrm{H}+\beta_{\mathrm{i}} \mathrm{I}}}
$$

Where $\beta_{0}=$ coefficient of the constant variable

$\beta_{\mathrm{h}}=$ coefficient of home ownership

$\beta_{\mathrm{i}}=$ coefficient of investors income/earnings

$\varepsilon_{\mathrm{i}}$ is the error term.

P-represents the logit of risk tolerance; it's the log of odds in which risk tolerance occurs. The risk tolerance score was ordered in to 5 levels; very high score 33 and above, above average 29-32, average score 23-28, below average 19-22 and very low 0-18.

\section{Findings}

\subsection{Home Ownership and Risk Tolerance}

Out of 141 investors owning homes, 40 had very high risk tolerance, 46 had average, 45 average and below average and 1 had low risk tolerance. 100 had very high risk tolerance; 116 above average, 122 average, 20 below average and 6 low risk tolerance. Home owners were more tolerant to risk and scored above average compared to non owners as indicated in Figure 2. They invested in their homes and therefore, they would be more willing to tolerate other risky investment options as compared to none owners. Anova results however showed that home ownership is not a significant factor on its own, in influencing individual investor risk tolerance among various groups interviewed, recording significance at a P Value of 0.710 as shown in the table below.

Table 1. Analysis of variance of home ownership and risk tolerance

\section{ANOVA}

RTS

\begin{tabular}{llllll} 
& Sum of Squares & Df & Mean Square & F & Sig. \\
\hline Between Groups & .127 & 1 & .127 & .138 & .710 \\
Within Groups & 463.623 & 503 & .922 & & \\
Total & 463.750 & 504 & & & \\
\hline
\end{tabular}




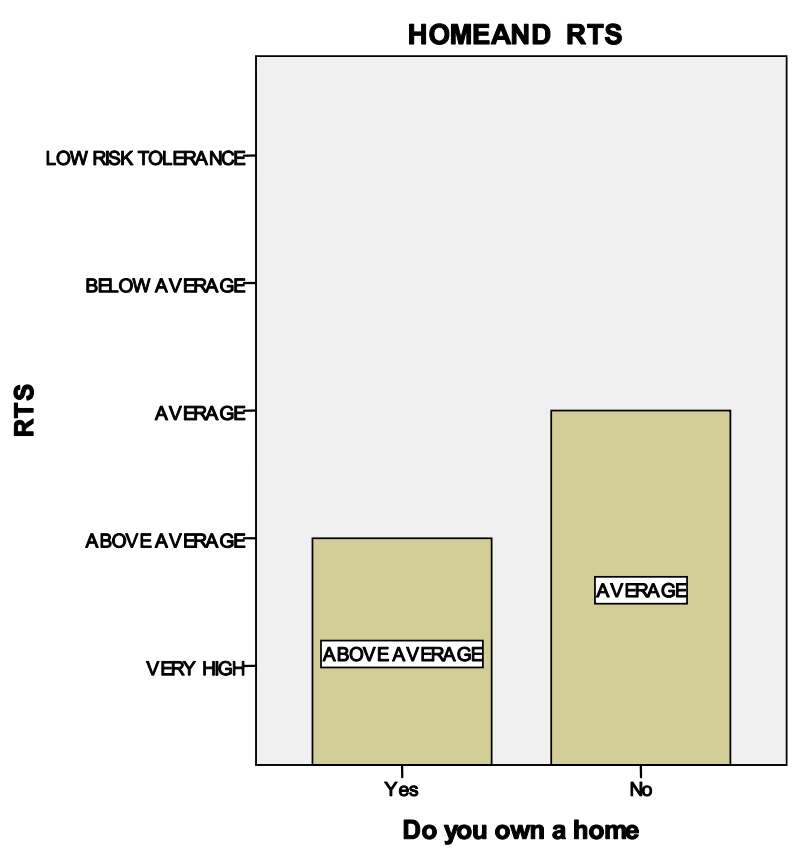

Bars show Mode

Figure 2. Home ownership and risk tolerance

\subsection{Individual Income and Risk Tolerance}

Out of those earning less than 30,000 per month, 47 had very high risk tolerance, 43 had above average, 64 average, 10 below average and 3 low risk tolerance. For those with 30,000 - 60,000 per month, 31 very high risks tolerant, 43 average and below average and 10 below average. Those earning 60,000-90,000 had 19 very high risk tolerance, 27 above average 18 average and 3 below average. Between 90,000 and 120,000, 20 very high, 13 above average, 8 average and 1 below average. Those with over 120,000, 11 had very high, 17 above average, 4 below average and 1 low risk tolerance. Similar trends were replicated in family income with exception of many families with over 120,000 exhibiting high risk. Analysis of variance among the income groups revealed quite significant results with a $P$ value of 0.014 , which is way below $\alpha=0.050$. At $95 \%$ confidence level, thus income influences risk tolerance among individual investor

Table 2. Income and risk tolerance ANOVA

\section{ANOVA}

RTS

\begin{tabular}{llllll} 
& Sum of Squares & Df & Mean Square & F & Sig. \\
\hline Between Groups & 11.188 & 4 & 2.797 & 3.155 & .014 \\
Within Groups & 396.288 & 447 & .887 & & \\
Total & 407.476 & 451 & & & \\
\hline
\end{tabular}




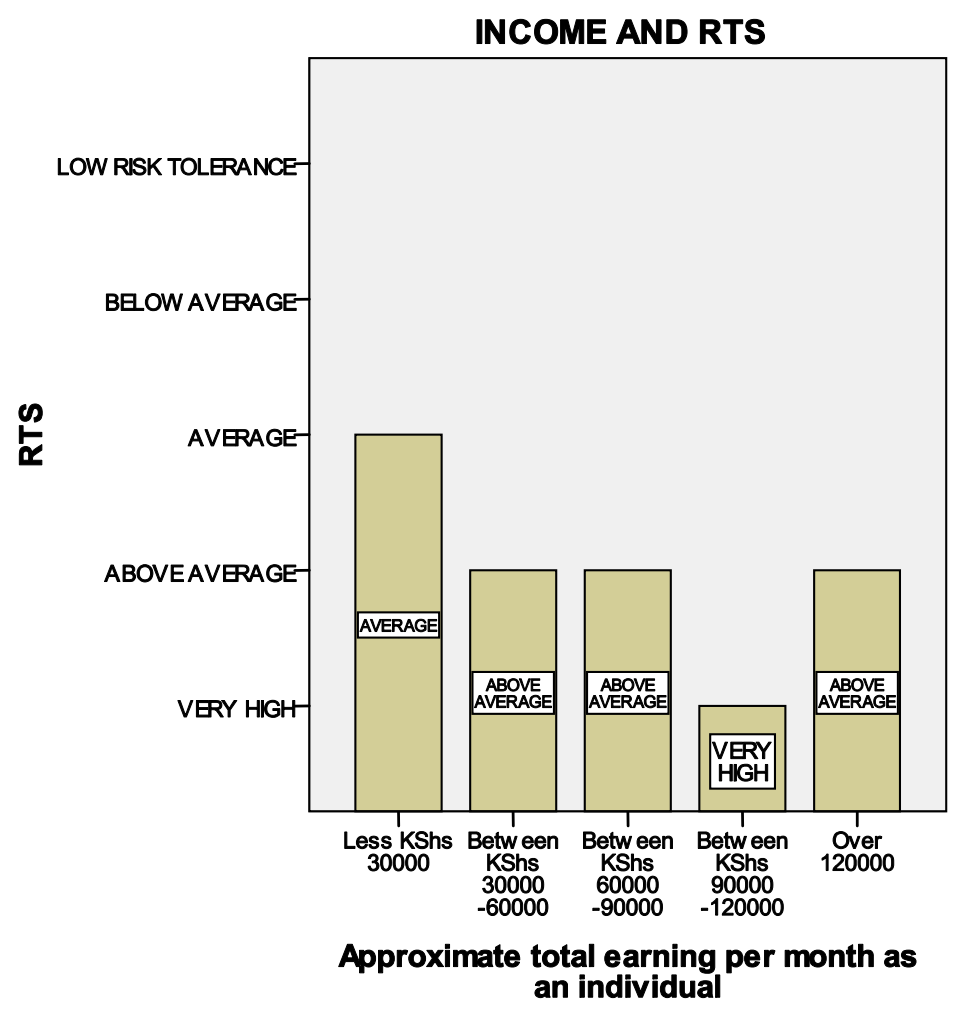

Bars show Mode

Figure 3. Individual income and risk tolerance

\subsection{Cross Tabulation}

Figure 4 provides further details of cross tabulation between income levels and home ownership among individual investors interviewed. Individuals earning less than Ksh 30000 per month ,whether with or without homes, scored a below average risk tolerance. Those earning 30000-60000 with homes scored below average, while those without homes in the same bracket were recording an average RTS, probably because they may be putting their wealth in risky investments to generate returns for purchasing homes. As the income band rose to between 60000-90000, those with homes increased in their RTS to above average, while those without remained at average. This may have been due to the home owners' asset allocation adjustment to attain a higher level of satisfaction, by adding ordinary stock to their portfolio. Between 90000-120000, investors with or without homes scored above average RTS, while over 120000 , the risk tolerance increased to very high for both categories. Generally risk tolerance increased as the income levels increased. 


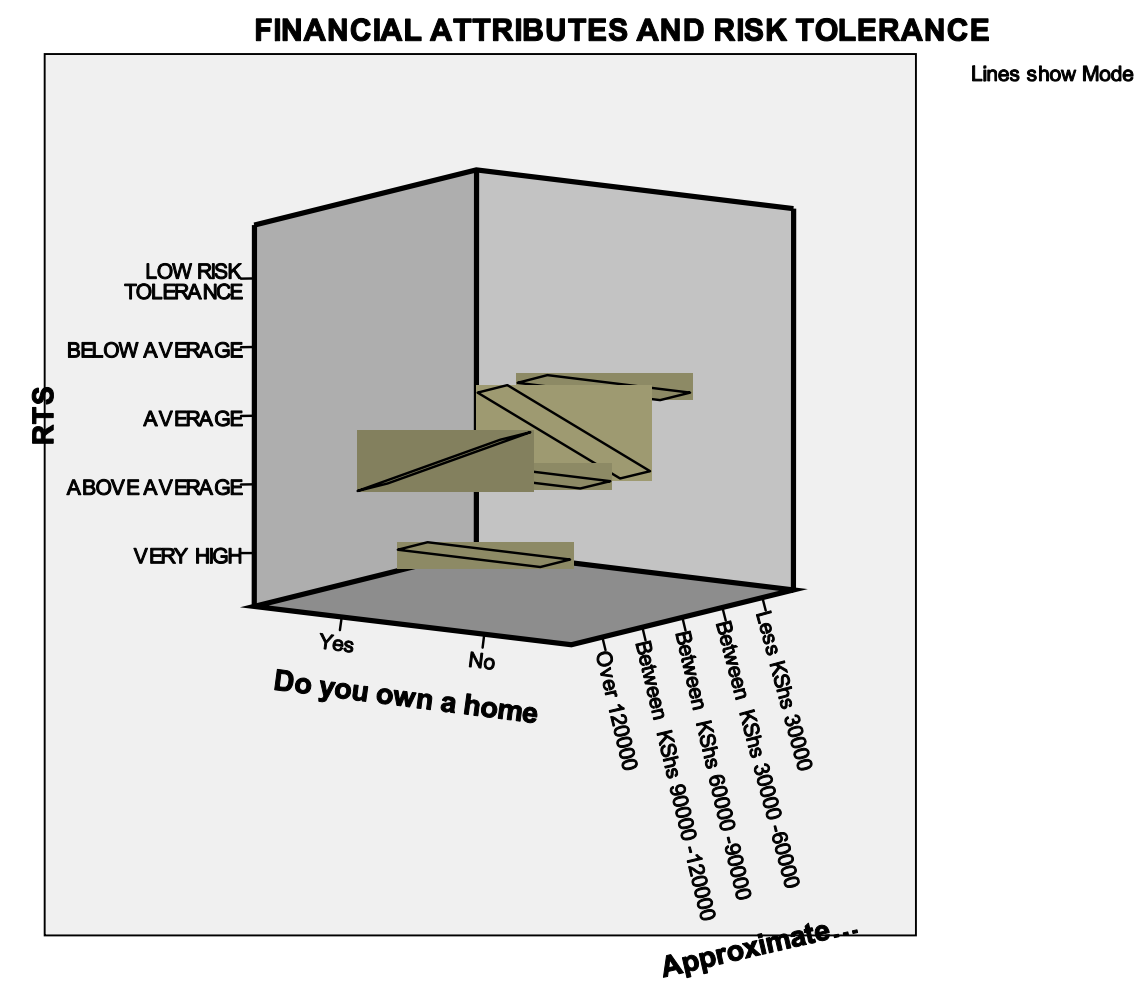

Figure 4. Financial attributes and RTS

\subsection{Ordinal logistic regression model (OLRM)}

SPPS ordinal procedure (Polytomous Universal Model -PLUM) was used to analyze the data to preserve the natural ordering of data. This is an extension of general regression model to logistic ordinal of general categories. It's a combination of parameter into probabilities of the dependent variable occurring. The risk tolerance score was ordered into 5 levels: very high score 33 and above, above average 29-32, average 23-28, below average 19-22 and very low 0-18. 84 respondents had very high score, 94 above average, 112 average, 22 below average and 2 low risk tolerance. The model fitted very well with significance level of $\mathrm{P}=0.027$, which is less than $\mathrm{P}=$ $0.050(\alpha=5 \%)$, meaning that the independent variables contributed jointly in the determination of risk tolerance to a significant extent.

Table 3. Ordinal logistic regression fitting information

\begin{tabular}{lllll}
\hline $\begin{array}{l}\text { Model Fitting Information } \\
\text { Model }\end{array}$ & -2 Log Likelihood & Chi-Square & Df & Sig. \\
\hline Intercept Only & 135.436 & & & \\
Final & 122.773 & 12.663 & 5 & .027 \\
\hline
\end{tabular}

Link function: Logit.

Home ownership was not a significant determinant at $\mathrm{P}=0.761$. Therefore, the null hypothesis that home ownership does not influence an individual investor risk tolerance was not rejected in the study. Home owners generally had higher RTS compared to none home owners, possibly because they are more stable in mind than the latter, having secured their basic quest in investment. For every single unit of home ownership from those with homes to those without, the expected ordered log of odds of risk tolerance increased by 0.060 , as the threshold of risk tolerance increased holding other factors constant as seen in appendix1 below. Income level of investors at sh. 90,000-120000 per month significantly influenced risk tolerance with $\mathrm{P}$ value of 0.006 . The null hypothesis that income is not a determinant of risk tolerance was therefore rejected. For every single unit increase for investors earning less than Ksh 30,000, the expected ordered log of odds of risk tolerance reduced 
by 0.042 as the threshold of risk tolerance increased, holding other factors constant. The same resulted into a reduction of 0.079 in the expected ordered log of odds for those earning between 30000-60000, a reduction of 0.420 for those earning between $60,000-90,000$ and1.077 for 90000-120000.Therefore, risk tolerance increased with income levels upto 120000 and after 120000 the risk tolerance level reduced to above average level. The upper income and/or wealthy individual investors could more easily afford to incur the losses resulting from a risky investment as established in studies by Grable and Lytton(1998) Faff et al. (2004) Watson and McNaughton (2007).

On the other hand, there may be a negative relationship between financial risk tolerance and wealth and/or income, especially at higher income levels. This is because individuals with lower income and wealth may be willing to take more risk for becoming wealthier as contended by Faff et al (2008), who found that there was a negative relationship between risk tolerance and income and wealth. Income and wealth are important factors that impact on the level of risk tolerance. It is assumed that financial risk tolerance increases with income and wealth. Because upper income and/or wealthy individuals can more easily afford to incur the losses resulting from a risky investment (Grable \& Lytton, 1998; Faff et al., 2004). Most of the research findings in relation to income and wealth support this hypothesis such as Van et al (2012) and Hoffmann et al (2012). On the other hand, there may be a negative relationship between financial risk tolerance and wealth and/or income. Because individuals with lower income and wealth may be willing to take more risk for becoming wealthier. Faff (2008), found that there was a negative relationship between risk tolerance and income and wealth.

\section{Conclusion}

Individual investors who owned homes were more risk tolerant than non home owners. This could be attributed to the "security" that home ownership provide for such individuals to tolerate more risk. Buying or constructing homes may in itself be a risky investment, because such individuals would take mortgage or loans with uncertainty of interest rates, thus such individuals are more inclined to risk in expectation of better returns. Investment advisors should therefore consider the home ownership status of their clients when setting investment policy on their behalf. Income levels are very significant in the determination of risk tolerance as seen in table 2 . Generally, risk tolerance increases with individual earnings, except for those earning over Ksh 120,000 per month. The wealthy may not be willing to accept higher risks, because as wealth accumulates, the proportion of loss increases. The main financial attribute that influences risk tolerance is income level as depicted in the results above; hence investment advisory service should be more inclined to individual's earnings.

Table 4. Ordinal logistic regression results

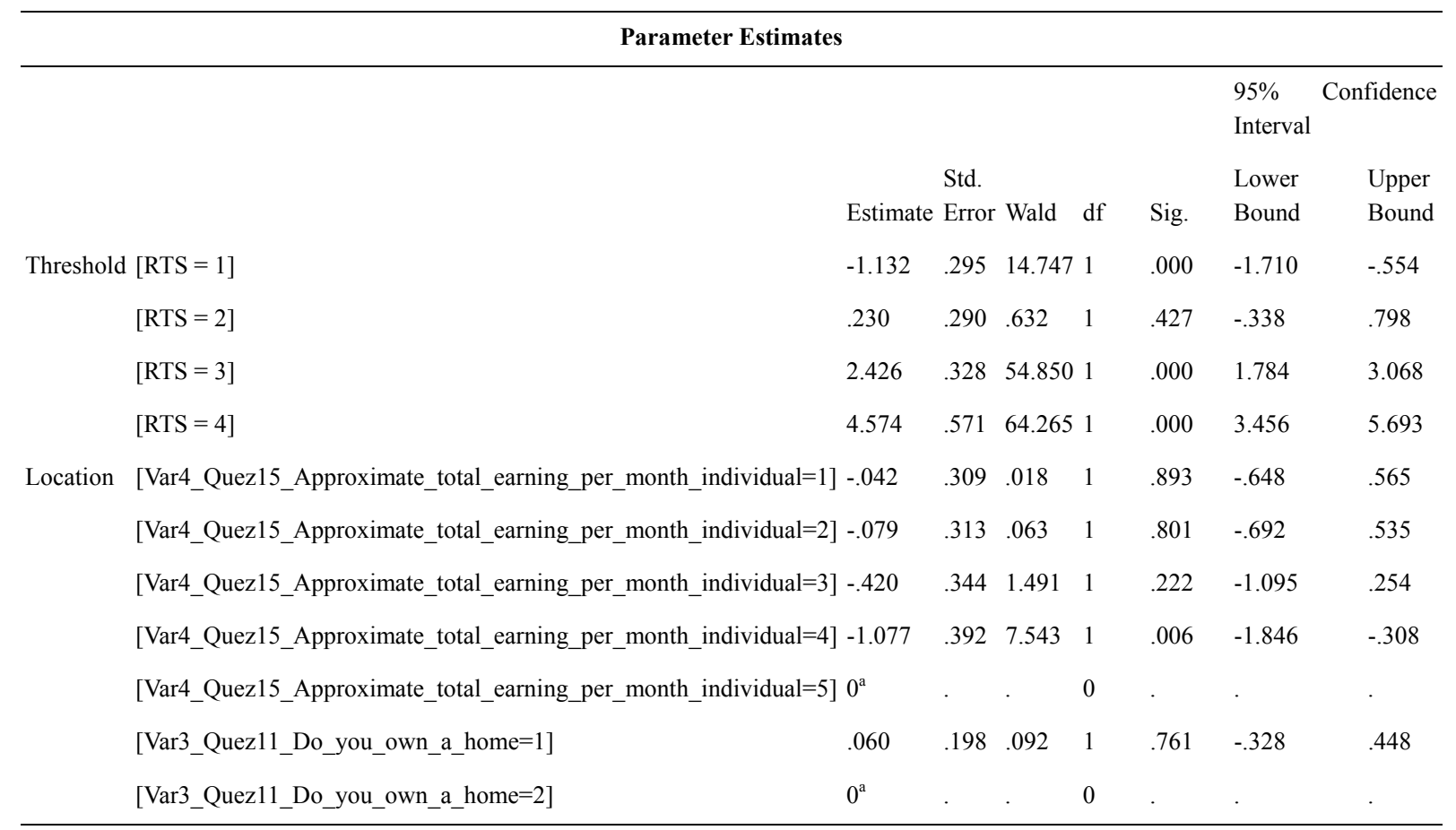

Link function: Logit.

a. This parameter is set to zero because it is redundant. 


\section{References}

Angelika, E., Axel. B., \& Euwals, R. (2007). Risk Attitude, Impatience and Asset Choice. Netherlands Bureau for Economic Policy Analysis.

Barsky, R. B., Kimball, M. S., Juster, F. T., \& Shapiro, M. D. (1997). Preference Parameters and Behavioural Heterogeneity: An Experimental Approach in the Health and Retirement Survey. Quarterly Journal of Economics, 112, 537-579. http://dx.doi.org/10.1162/003355397555280

CMA. (2010). Quarterly Statistical Bulletin, Capital Markets Authority 2010.

Cooper, D. R., \& Schindler, P. S. (2008). Business Research Methods (10th ed.). Mc Grawhill co.

Davey, G. (2002). Scientific Risk Profiling. Proquest, Sydney.

Donkers, B. B., \& Soest, V. (1999). Estimating Risk using Lotteries: A large sample approach. Journal of Risk \& Uncertainty, 22(2), 165-195. http://dx.doi.org/10.1023/A:1011109625844

Faff, R. W., \& Hallan, M. D. (2004). An Empirical Investigation of Investor Risk Tolerance. Financial Services Review, 13, 57-78.

Faff, R., Mulino, D., \& Chai, D. (2008). On the linkage between financial Risk Tolerance and Risk aversion. The Journal of Financial Research, 31, 1-23. http://dx.doi.org/10.1111/j.1475-6803.2008.00229.x

Grable, J. E. (2000). Financial Risk Tolerance and Additional Factors That Affect Risk Taking in Everyday Money Matters. Journal of Business and Psychology, 14, 625-630. http://dx.doi.org/10.1023/A:1022994314982

Grable, J. E., \& Joo, S. (1997). Determinants of Risk Preference: Implication for the Family and Consumer Science Professionals. Family Economics Management Biennial, 2, 19-24.

Grable, J. E., \& Lytton, R. H. (1998). Testing the Efficacy of Demographics as Differentiating and Classifying Factors. Financial Counseling and Planning, 9, 61-74.

Grable, J. E., \& Lytton, R. H. (2003). Assessing Financial Risk Tolerance: Do Demographic, Socioeconomic and Attitudinal Factors Work? Family Relations and Human Development / Family Economics and Resource Management Biennial, 3, 80-88.

Hanna, S., \& Chen, P. (1997). Subjective and Objective Risk Tolerance: Implications for Optimal Portfolios. Financial Counseling and Planning, 8(2), 17-26.

Hayness, G. W. (2001). Attitude toward Risk and Risk taking behavior of business owning family. Journal of Consumer Affairs, 35(2), 307-325. http://dx.doi.org/10.1111/j.1745-6606.2001.tb00116.x

Hoffman, A. O. I., Post, T., \& Pennings, J. M. E. (2012). Individual Investor Perceptions and Behaviour during the Financial Crisis. Journal of Banking and Finance, Elsevier.

Kelinger, F. N. (2004). Foundations of Behavioral Research (2nd ed.). Holt \& Winston.

NSE Handbook. (2008). Business Development, Nairobi Stock Exchange.

Palsson, A. M. (1996). Does the Degree of Risk Aversion vary with Household Characteristics? Journal of Economic Psychology, 17, 771-787. http://dx.doi.org/10.1016/S0167-4870(96)00039-6

Paun, C., Radu, M., \& Lulian, B. (2007). Empirical Evidence of Risk Aversion for Individual Romanian Capital Market Investors. MPRA, 6842, 22.

Sekaran, U. (2003). Research Methods a Skill Building Approach (4th ed.). John Wiley \& Sons.

Sung, J., \& Hanna, S. (1996). Factors Related To Risk Tolerance. Financial Counseling and Planning, 7, 11-20.

Van, G. V., Micheyluk, D., \& Davey, D. (2012). Longitudinal Study of Financial Risk Tolerance in Australia. Journal of Economic Psychology, Elsevier.

Wang, C., \& Hanna, S. (2007). Racial Ethnic Disparities in Stock ownership: A Decomposition Analysis. Consumer Interest Annual, 53.

Wang, C., \& Hanna, S. (2007). Risk Tolerance and Stock Ownership of Business Owning Households. Association for financial planning \& counseling education.

Watson, J., \& McNaughton, M. (2007). Gender Differences in Risk Aversion and Expected Retirement Benefits. Financial Analysts Journal, 63(4), 52-62. http://dx.doi.org/10.2469/faj.v63.n4.4749 